\title{
Revisiting intra-arterial drug delivery for treating brain diseases or is it "déjà-vu, all over again"?
}

\author{
Shailendra Joshi, Jason A. Ellis' ${ }^{1}$ Charles W. Emala
}

\begin{abstract}
For over six decades intra-arterial (IA) drugs have been sporadically used for the treatment of lethal brain diseases. In recent years considerable advance has been made in the IA treatment of retinoblastomas, liver and locally invasive breast cancers, but relatively little progress has been made in the treatment of brain cancers. High resting blood flow and the presence of the blood-brain barrier (BBB), makes IA delivery to the brain tissue far more challenging, compared to other organs. The lack of advance in the field is also partly due to the inability to understand the complex pharmacokinetics of IA drugs as it is difficult to track drug concentrations in sub-second time frame by conventional chemical methods. The advances in optical imaging now provide unprecedented insights into the pharmacokinetics of IA drug and optical tracer delivery. Novel delivery methods, improved IA drug formulations, and optical pharmacokinetics, present us with untested paradigms in pharmacology that could lead to new therapeutic interventions for brain cancers and stroke. The object of this review is to bring into focus the current practice, problems, and the potential of IA drug delivery for treating brain diseases.A concerted effort is needed at basic sciences (pharmacology and drug imaging), and translational (drug delivery techniques and protocol development) levels by the interventional neuroradiology community to advance the field.
\end{abstract}

Key words: Brain diseases, drug delivery, intra-arterial

\section{INTRODUCTION}

For over six decades intra-arterial (IA) drugs have been proposed for the treatment of lethal brain diseases. ${ }^{[1-4]}$ Recent reports of super-selective intraarterial (IA) injections of bevacizumab for treating human gliomas have brought IA drug delivery back into focus ${ }^{[5-8]}$ In contrast to treatment of brain cancers the interest in IA chemotherapy for treating liver and breast cancers has considerably increased in the last three decades [Figure 1]. ${ }^{[9,10]}$ Major advances have also been made in using IA chemotherapy of retinoblastomas to avoid surgical removal and improve function. ${ }^{[11-15]}$ High

\begin{tabular}{|l|l|}
\hline \multicolumn{2}{|c|}{ Access this article online } \\
\hline Quick Response Code: & Website: \\
\hline & www.jnaccjournal.org \\
\cline { 2 - 2 } & \\
\hline
\end{tabular}

resting cerebral blood flow and the presence of the blood brain barrier (BBB), makes IA drug delivery to the brain far more challenging compared to other organs.

In the last two decades endovascular surgery has opened new vistas for treating neurological diseases. With easy access to distal cerebral circulation provided by modern micro-catheters, and finite diffusion distances within the capillary networks, one would expect that it would be easy to demonstrate the effectiveness of IA drugs. Unfortunately, this is yet to be realised or worked out. The failure in treating brain diseases with IA drugs is in part due to a continuing lack of understanding of IA pharmacokinetics, unavailability of convenient high-speed drug concentration measurement methods, poor rationalisation of drug injection protocols and the use of drugs and formulations without adequate pharmacokinetic justifications -many of which were never developed for IA use in the first place.

Yet, in-extremis, IA drugs are used for the treatment many other brain diseases beyond cancers, such as stroke, ${ }^{[16-19]}$ cerebral vasospasm, ${ }^{[20-24]}$ raised intracranial pressure, ${ }^{[25]}$

Departments of Anesthesiology, and ${ }^{1}$ Neurosurgery, College of Physicians and Surgeons of Columbia University, New York, NY

Address for correspondence:

Dr. Shailendra Joshi, Department of Anesthesiology, College of Physicians and Surgeons of Columbia University, P and S P Box 46, 630 West $168^{\text {th }}$ Street, New York, NY-10032, US. E-mail: sj121@columbia.edu 


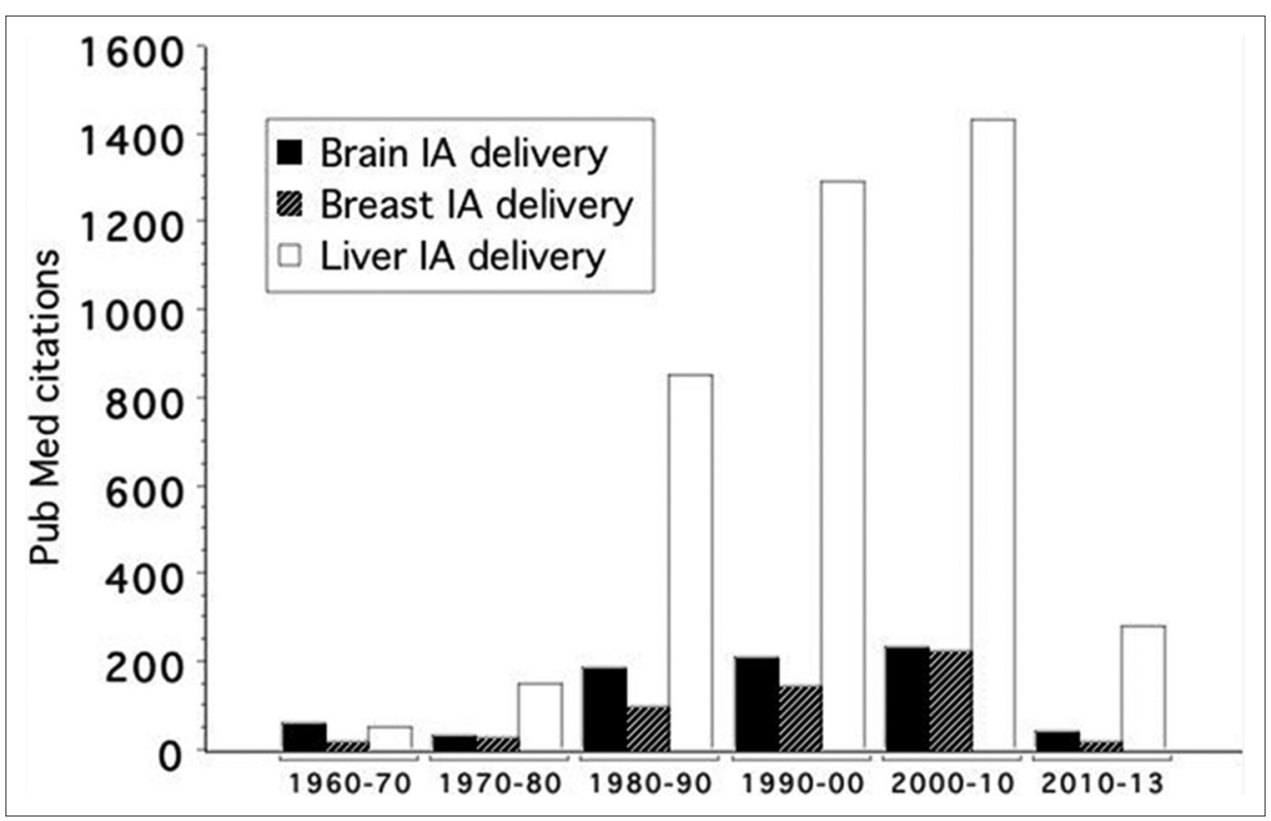

Figure 1: Pubmed citations for intraarterial chemotherapy of treatment of liver, breast and brain cancers in the last five decades: IA chemotherapy is $2-5 \mathrm{X}$ as effective as intravenous chemotherapy for metastatic liver disease and $90 \%$ of locally invasive breast cancers respond to IA chemotherapy but there seems to be little improvement in the outcome of brain cancers

and infections. ${ }^{[2,27]}$ Several anaesthetic drugs have been safely been used in diagnostic neurology for localisation of brain functions, since 1949, which reflects the safety of IA delivery. ${ }^{[28-33]}$ In recent years, monoclonal antibodies, stem cells, viral vectors, liposomes and nanoparticles have been delivered by IA injections - all of which could play a major role in the future treatment of brain diseases. ${ }^{[34]}$ Improved IA delivery could enhance onset and effectiveness of smart nano-scale drug delivery vehicles that are in development. Considering the practice, pitfalls, and the potential of IA drugs, this review makes the case for reassessing IA drugs and it elaborates on the novel treatments that IA drugs could offer. A concerted effort is needed at basic sciences (pharmacology and drug imaging), and translational research (drug delivery techniques and protocol development) levels by the interventional neuroradiology community to advance the field.

\section{THE CHECKERED HISTORY OF IA DRUGS}

In 1929, motivated in part by the desire to deliver drugs, Werner Forssmann demonstrated on himself the feasibility of cardiac catheterisation. ${ }^{[35]}$ Two decades later Wada introduced IA anaesthetic drugs for localising brain functions and the Wada test is still used as a diagnostic tool for epilepsy treatment. ${ }^{[28]}$ In the 1950s, Klopp et al., pioneered the use of intracarotid nitrogen mustard to treat brain cancers. ${ }^{[1,36,37]}$ In the 1960s, Charles Wilson systematically investigated chemotherapy of brain tumours including IA delivery ${ }^{[38-40]}$ In the 1970s, Stanley
Rapoport introduced intracarotid osmotic agents for disrupting the blood-brain barrier (BBB). ${ }^{[4]}$ In the 1980s, Oldfield's group at the National Institutes of Health (NIH) made a concerted effort to improve intracarotid chemotherapy and went as far as using extracorporeal haemofiltration to minimise systemic toxicity. ${ }^{[42-45]}$ Unfortunately, there was little clinical impact of even such intense interventions while others reported unexplained focal neurological complications during IA infusions. ${ }^{[46-50]}$ Consequently, the interest in IA drugs waned by the early 1990s. ${ }^{[51]}$ Edward Neuwelt was one of the few people who continued the work, using IA mannitol for BBB disruption. ${ }^{[52]}$ In hindsight though, the failures in 1980s were particularly unfortunate as they happened at the dawn of the modern endovascular era. ${ }^{[53,54]}$

\section{THE FUNDAMENTAL PRINCIPLES OF IA DRUG DELIVERY}

In simulations of steady-state IA infusions, Dedrick et al., showed that IA drug delivery was most effective when there is: (i) low regional blood flow; (ii) high regional extraction; and (iii) high systemic clearance; and that the advantage of IA delivery wanes with prolonged infusions [Figure 2]. ${ }^{[5]}$ Other investigators at the time pointed to the problem of "streaming". Streaming occurs with low volumes drug infusions, when the currents within the arterial stream determine the distribution of the drugs. Maldistribution due to streaming could result in toxic concentrations in some territories while bypassing others. ${ }^{[56-59]}$ Streaming was probably responsible for some of the focal neurological 


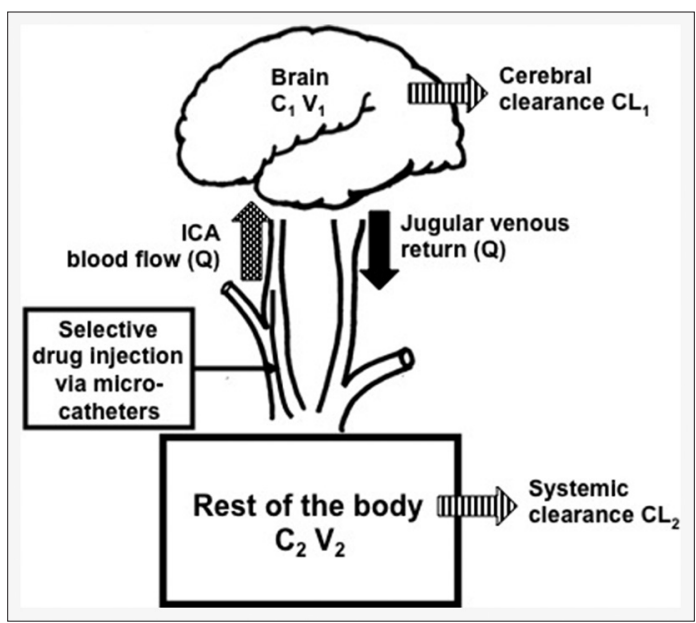

Figure 2: Model of intracarotid drug delivery, C1 C2 and V1 V2 are concentrations and volumes in the brain (1) and remainder of the body (2), respectively. $Q$ is the regional blood flow and CL1 and CL2 are cerebral and remaining body clearances. Dedrick RL 1988, J Natl Cancer Inst 80, (2) 84-89

complications reported with IA chemotherapy and it also explains some of the failures of pharmacokinetic models of IA drug delivery. ${ }^{[60]}$ The Dedrick model also reveals the problems in IA drug delivery to the brain, due to the presence of BBB which limits drug uptake, and the high resting blood flow to the organ. Technological advances in endovascular surgery now provide new opportunities to improve IA drug delivery by transiently reducing blood flow and injecting bolus of drugs as predicted by the Dedrick model. ${ }^{[55]}$ Injecting drugs as boluses during transient cerebral hypoperfusion not only enhances arterial concentrations, it avoids streaming and helps to localise drug interventions at specific sites.

It is well accepted that under normothermic conditions the brain can withstand 3 minutes of ischaemia. Several investigators have used transient flow arrest to better localise drug delivery. In 2004, Yamane et al., demonstrated the safety and efficacy of balloon occlusion during treatment of 187 paediatric cases of retinoblastoma. No significant complications, except transient bradycardia, were reported in 563 treatments of balloon assisted super-selective ophthalmic artery infusions. ${ }^{[61]}$ Recently, Riina et al., used 3-min occlusion with 2-min reperfusion cycles to treat brain stem glioma with bevacizumab over a period of an hour with good tumour response at 24 hours. ${ }^{[6]}$ Arresting blood flow by transiently suppressing cardiac activity to localise cyanoacrylate glue has been used in the treatment of high flow cerebral arteriovenous malformations. In a series of cases Pile-Spellman and Young described the safe use of adenosine-induced cardiac arrest for embolisation of such malformations. ${ }^{[62-64]}$

Therefore, faced with lethal brain diseases, it is not hard to justify the potential risk of stroke due transient cerebral hypoperfusion (TCH) or even flow arrest, if it can localise therapeutic agents and/or dramatically improve drug delivery. ${ }^{[62-64]}$ In experimental animals, reduction in blood flow can improve drug delivery three to ten fold compared to IA injections made during normal blood flow. ${ }^{[34]}$ During TCH, IA drug delivery can be further enhanced by optimising bolus injection parameters and by using drug formulations with rapid tissue uptake. ${ }^{[65]}$

\section{Optimising bolus injections}

The objective of bolus design is to match the area under the arterial blood concentration-time curve to tissue uptake. During TCH, injecting drugs as boluses offers a number of advantages besides avoiding streaming. First, the bolus volume generates high arterial concentrations exposing the brain tissue to virtually pure drug. This decreases the contact with blood components and binding proteins to generate high free drug concentrations. Second, bolus injections during TCH increase the transit time through the cerebral circulation from 1 second to as long as 1-2 minutes in experimental animals. High concentrations of free drugs, the prolonged capillary contact and short inter-capillary diffusion distance, all combine to significantly improve drug delivery when $\mathrm{TCH}$ is combined with bolus injections. ${ }^{[66]} \mathrm{A}$ good example of this is the cationic formulations of liposomes dramatic improvements (100 fold) in drug delivery are possible compared to intravenous delivery of the same liposomes. ${ }^{[67]}$

In theory, one can manipulate three parameters of bolus injections: ${ }^{[1]}$ (i) Volume, (ii) concentration, and (iii) frequency. The volume of the bolus should be such that it ensures maximum capillary contact, i.e., able to displace blood in the arteries and the capillaries but not the veins ${ }^{[65]}$ Excessive volume can result in rapid transit though the capillary networks to decrease the time available for drug uptake. The concentration of the drug in the bolus is determined by the brain tissue uptake. The frequency of bolus injection should ensure steady replenishment of drug in the capillary networks as the concentration of the drug declines due to tissue uptake. In addition, one has to consider the total dose of the drug, its local toxicity and whether repeat hypoperfusion bolus injection cycles will be necessary to treat the underlying pathology. ${ }^{[6]}$

\section{Optimising IA drugs and formulations to improve first pass drug extraction}

It is often not realised that drugs are seldom screened or developed for IA administration. Most reports of IA treatments describe the off- label use of intravenous (IV) drugs. For maximum benefit from IA delivery, drugs have to be rapidly extracted during their first pass through the cerebral circulation. ${ }^{[55]}$ One of the reasons for the wide application of IA drugs for liver cancer 
treatment is the high hepatic extraction. For example, hepatic extraction of floxuridine can be as high as $49-99 \%$ after hepatic artery infusion. ${ }^{[68-70]}$ However, drugs and drug formulations can also be optimised for first pass extraction by brain tissue. A good example of this, again are the liposomal formulations. Cationic magnetic liposomes are almost 15 times more effective with IA delivery compared to IV administration. ${ }^{[71]}$ When given intravenously, cationic liposomes are rapidly sequestered in non-target organs. However, when injected intraarterially during $\mathrm{TCH}$, not only are the particles spared of sequestration by non-target organs but they also avoid exposure to plasma proteins which protects their surface charge. We have observed that IA injections of charge neutral liposomes have poor uptake by brain tissue while cationic liposomes are readily retained. Furthermore, bolus IA injections of cationic liposomes achieve three to four-fold-greater tissue concentrations during TCH compared to injections during normal blood flow. ${ }^{[67,72]}$

\section{Optimising drug design}

The drug uptake across the $\mathrm{BBB}$ is related to the permeability surface area product (PSA) of a drug. ${ }^{[73]} \mathrm{By}$ modifying the drug molecule, such as, decreasing polar groups or increasing aliphatic groups, one can increase the PSA. The approach was used to augment brain selective drug delivery of chlorambucil tri-butyl ester after IV injection. ${ }^{[74]} \mathrm{A}$ similar approach could augment the delivery of IA drugs.

\section{Receptor and transporter conjugated drugs}

Many drugs have been conjugated with transporter and receptor ligands to increase drug delivery across the BBB via these physiological mechanisms. ${ }^{[75]}$ For example, OX-26 monoclonal antibody to transferrin receptor (TFR-1) was developed to target drug delivery to the brain tissue after IV injections. ${ }^{[6,77]}$ The TFR-1 receptors trigger receptor-mediated endocy tosis capable of delivering large drug cargos across the BBB. ${ }^{[78]}$ However, IV injections of these compounds were not very effective due to the non-targeted liver uptake. In the brain, the TFR-1 receptor is more abundantly expressed in tumours compared to the normal neuronal or glial tissue and could provide a valuable ligand for targeting chemotherapeutic drugs. ${ }^{[7]}$ Improved IA methods of drug delivery might be able to selectively target brain tumours.

\section{Cationic carriers and IA drug delivery}

Cationic peptides and drugs are capable of penetrating the $\mathrm{BBB}$ and their effective delivery could be further enhanced by TCH assisted delivery. ${ }^{[80-83]}$ Furthermore, nanoparticles have been already conjugated with low molecular weight protamine to enhance tissue uptake. ${ }^{[84]}$ Beside protamine there are other cationic carrier systems in the brain, such as for cationic albumin (sometimes called the super-carrier) that can also deliver drugs across the BBB. ${ }^{[85-89]}$ In recent years cationic cell penetrating peptides such as Trans-activator of transcription (TAT) derived from human immuno-deficiency virus have emerged as vehicles for drug delivery across the BBB. ${ }^{[90-93]}$ Dramatic improvements in IA drug delivery might be possible if drugs were conjugated to cationic carriers and injected during $\mathrm{TCH}$ in a manner similar to cationic liposomes. Preliminary data with TAT suggested that is indeed the case. ${ }^{[94]}$

\section{Novel IA drugs}

Another approach to IA drug development could be the development of drugs that have exceedingly short biological half-lives, such as adenosine. In non-human primates in a head-to-head comparison between intracarotid sodium nitroprusside $\left(\mathrm{T}_{1 / 2} \beta\right.$ of $\left.90 \mathrm{~s}\right)$ and adenosine $\left(\mathrm{T}_{1 / 2} \beta\right.$ of $\left.1 \mathrm{~s}\right)$, IA sodium nitroprusside reduced systemic blood pressure but had no effect on cerebral blood flow (CBF) while adenosine in large doses did not affect the blood pressure but dramatically increased CBF. ${ }^{[95]}$ Adenosine provides a conceptual prototype of IA drugs, whose biological half-life is so short that it is significantly metabolised during transit through cerebral circulation to minimise systemic side effects. Such short-acting drugs will be invaluable when multiple drugs are used for dynamic IA interventions based on rapidly changing tissue needs.

\section{ADDITIONAL STRATEGIES FOR IMPROVING IA DRUG DELIVERY}

Besides balloon occluding catheters, CBF can also be reduced safely by induced hypothermia, deep IV anaesthesia, or by hyperventilation. Hypothermia being neuroprotective could be particularly useful to enhance safety and the duration of TCH. The method of choice for reducing blood flow, whether sustained or transient, will probably depend on the individual drug.

\section{Systemic rescue}

Oldfield et al., used extracorporeal haemofiltration of jugular venous blood to reduce systemic toxicity. ${ }^{[42-44]}$ Other investigators have used systemic antidotes concurrent with IA injections, such as thiosulphates, to neutralise re-circulating chemotherapeutic drugs. Classical forced alkaline or acid diuresis can also eliminate the recirculating drug. In recent years cyclodextrins have become available as non-specific chelating agents that could be used for the purpose reducing systemic toxicity.

\section{NOVEL TOOLS TO INVESTIGATE IA DRUGS}

If we accept the proposition that there can be significant improvements to IA drug delivery then, we have 
to determine how best to rapidly advance the field. A fundamental hurdle to the understanding of IA drug delivery has been the inability to track drug concentration measurements in real-time in a typical laboratory or clinical setting. Chemical analysis of tissue samples does not provide site-specific histories. Although multiple tissue biopsies have been taken from the same animal to obtain time histories, there is cumulative injury to the tissue. Microdialysis is not readily feasible for IA studies if bolus injections are used due to the time required for dialysis equilibrium. Pharmacokinetic studies are feasible with magnetic resonance imaging and radioisotopes but logistics and cost can be prohibitive for high volume research.

In contrast, novel optical methods can help us better understand the pharmacokinetics of IA drugs. Optical methods, such as diffuse reflectance spectroscopy, ${ }^{[96-99]}$ multi-spectral and hyperspectral imaging, spatial frequency domain imaging (SFDI), ${ }^{[100-102]}$ confocal microscopy and spectroscopy, and even optical coherence tomography provide us with novel pharmacokinetic tools. Collectively, spatial and temporal resolution of optical methods is bound to generate novel insights in drug delivery and the mechanisms of drug resistance. It is generally held that future brain treatments will be based on macromolecules, such as antibodies, peptides, gene fragments, liposomes or nanoparticles. Such macromolecules can easily be tagged with optical tracers without altering their pharmacokinetic properties. For drugs with a stable spectrum, distinct from haemoglobin and deoxyhaemoglobin, ultra-fast tissue non-invasive drug concentrations measurements are feasible at several times per second with diffuse reflectance spectroscopy and multispectral imaging. ${ }^{[97]}$ Diffuse reflectance spectroscopy can track multiple chromophores, that permits quantification of BBB permeability, using a tracer like indocyanine green, while tracking tissue drug concentrations. ${ }^{[103]}$ Multispectral imaging could help to elucidate tissue surface drug concentrations for those that have wavelength specific excitation and emission at sampling rates of hundreds of times per second. Hyperspectral imaging could also provide a planar map of spectral changes after drug injection that could be used for determining tissue drug concentrations. Both confocal microscopy and hyperspectral imaging will require time for image acquisition; however, the former method may provide a pharmacokinetic tomogram post delivery while tissue spectroscopy may quantify free, bound and metabolised drug. In theory, in vivo optical pharmacokinetic tomography is possible in large tissue volumes (several $\mathrm{cm}$ ) with SFDI but such application is still in development. ${ }^{[101,102]}$ As nanoparticle-based drug delivery evolves "optical pharmacokinetic tomography" will be critical in mapping macromolecules whose diffusion is likely to be restricted in the highly compartmentalised brain tissue and not just by the BBB. ${ }^{[104]}$

\section{POTENTIAL IMPACT OF IA TREATMENTS}

Effective, timely and safe drug delivery to brain tissue is perhaps the most persistent and significant problem in translational neuroscience research. Most of the neuropharmaceuticals that are in development will not cross the BBB. William Pardridge therefore emphasised that drug discovery and drug delivery must go hand in hand. ${ }^{[105]}$ The ability of IA drugs to target specific regions of the brain pathology, rapidly achieving therapeutic concentrations with minimal systemic exposure, with the possibility of administering multiple drugs at the same time, could open new avenues for the treatment for brain diseases. Due to the complex matrix of neurological injuries, future cures for brain diseases might require curative cocktails, not magic bullets. Administration of multiple drugs by the IV route is often limited because of drug interactions and additive side effects. However, multiple drugs could be administered as pulses via the IA route. Such an approach might offer innovative treatments. In the case of cerebral vasospasm a pulse of IA adenosine, a potent short acting vasodilator, might transiently dilate the spastic arteries to permit delivery of less potent but longer acting vasodilator, such as nicardipine. ${ }^{[106]}$ In brain cancer treatment, IA drugs could offer chemo-ablative therapy for the core of the tumour that is devoid of any function and anti-mitotic anti-angiogenic therapy in the peripheral zone with salvageable functions. For stroke, multiple IA drugs might be injected while imaging injury parameters. ${ }^{[107]}$ Such highly individualised and dynamic IA interventions could enable future molecular reconstructive neurosurgery that could improve the quality of survival not just provide a cure.

\section{CONCLUSIONS}

In conclusion, the advances in endovascular neurosurgery now permit the development of more sophisticated IA drug delivery protocols while those in optical engineering promise to reveal the hitherto ill-understood pharmacokinetics of IA drugs. It's not “Déjà-vu, all over again!" as Mr. Yogi Berra said. To the contrary, novel delivery methods, improved IA drugs, and optical pharmacokinetics, present untested paradigms in pharmacology and offer hope to patients with intractable neurological diseases. A concerted effort is needed at basic sciences (pharmacology and drug imaging), and translational research (drug delivery techniques and protocol development) levels by the interventional neuroradiology community to advance the field. 


\section{REFERENCES}

1. Klopp CT, Alford TC, Bateman J, Berry GN, Winship T. Fractionated intra-arterial cancer; chemotherapy with methyl bis amine hydrochloride; a preliminary report. Ann Surg 1950;132:811-32.

2. Bonner CD, Thurman A, Homburger F. A critical study of regional intra-arterial nitrogen mustard therapy in cancer. Ann Surg 1952;136:912-8.

3. Westbury G. Treatment of advanced cancer by extracorporeal perfusion and continuous intra-arterial infusion. Proc R Soc Med 1962;55:643-6.

4. Westbury G. Continuous intra-arterial infusion and intermittent intra-arterial injection. Proc $R$ Soc Med 1963;56:655-8.

5. Boockvar JA, Tsiouris AJ, Hofstetter CP, Kovanlikaya I, Fralin S, Kesavabhotla K, et al. Safety and maximum tolerated dose of superselective intraarterial cerebral infusion of bevacizumab after osmotic blood-brain barrier disruption for recurrent malignant glioma. Clinical article. J Neurosurg 2011;114:624-32.

6. Riina HA, Burkhardt JK, Santillan A, Bassani L, Patsalides A, Boockvar JA. Short-term clinico-radiographic response to super-selective intra-arterial cerebral infusion of Bevacizumab for the treatment of vestibular schwannomas in Neurofibromatosis type 2. Interv Neuroradiol 2012;18:127-32.

7. Riina HA, Fraser JF, Fralin S, Knopman J, Scheff RJ, Boockvar JA. Superselective intraarterial cerebral infusion of bevacizumab: A revival of interventional neurooncology for malignant glioma. J Exp Ther Oncol 2009;8:145-50.

8. Shin BJ, Burkhardt JK, Riina HA, Boockvar JA. Superselective intra-arterial cerebral infusion of novel agents after blood-brain disruption for the treatment of recurrent glioblastoma multiforme: A technical case series. Neurosurg Clin North Am 2012;23:323-9.

9. Wallace S, Carrasco CH, Charnsangavej C, Richli WR, Wright K, Gianturco C. Hepatic artery infusion and chemoembolization in the management of liver metastases. Cardiovasc Intervent Radiol 1990;13:153-60.

10. Aigner KR. Intra-arterial infusion: Overview and novel approaches. Semin Surg Oncol 1998;14:248-53.

11. Abramson DH, FrancisJH, Dunkel IJ, Marr BP, Brodie SE, Gobin YP. Ophthalmic artery chemosurgery for retinoblastoma prevents new intraocular tumors. Ophthalmology 2013;120:560-5.

12. Francis JH, Barker CA, Wolden SL, McCormick B, Segal K, Cohen G, et al. Salvage/adjuvant brachytherapy after ophthalmic artery chemosurgery for intraocular retinoblastoma. Int J Radiat Oncol Biol Phys 2013;87:517-23.

13. Francis JH, Gobin YP, Brodie SE, Marr BP, Dunkel IJ, Abramson DH. Experience of intra-arterial chemosurgery with single agent carboplatin for retinoblastoma. $\mathrm{Br} \mathrm{J}$ Ophthalmol 2012;96:1270-1.

14. Francis JH, Gobin YP, Dunkel IJ, Marr BP, Brodie SE, Jonna G, et al. Carboplatin +/- topotecan ophthalmic artery chemosurgery for intraocular retinoblastoma. PLoS One 2013;8:e72441.

15. Gobin YP, Dunkel IJ, Marr BP, Francis JH, Brodie SE, Abramson DH. Combined, sequential intravenous and intra-arterial chemotherapy (bridge chemotherapy) for young infants with retinoblastoma. PLoS One 2012;7:e44322.

16. Ciccone A, Valvassori L, Nichelatti M, Sgoifo A, Ponzio M, Sterzi R, et al. SYNTHESIS Expansion Investigators. Endovascular treatment for acute ischemic stroke. N Engl J Med 2013;368:904-13.

17. Duraes AR, Brito JC. Images in clinical medicine. Selective intraarterial thrombolysis for cardioembolic stroke. N Eng J Med 2012;367:e24.
18. Kim JW, Jeon P, Kim GM, Bang OY, Byun HS, Kim KH. Local intraarterial tirofiban after formation of anterograde flow in patients with acute ischemic stroke: Preliminary experience and short term follow-up results. Clini Neurol Neurosurg 2012;114:1316-9.

19. Park H, Hwang GJ, Jin SC, BangJS, Oh CW, Kwon OK. Intra-arterial thrombolysis using double devices: Mechanicomechanical or chemicomechanical techniques. J Korean Neurosurg Soc 2012;51:75-80.

20. Flexman AM, Ryerson CJ, Talke PO. Hemodynamic stability after intraarterial injection of verapamil for cerebral vasospasm. Anesth Analg 2012;114:1292-6.

21. Kerz T, Boor S, Beyer C, Welschehold S, Schuessler A, Oertel J. Effect of intraarterial papaverine or nimodipine on vessel diameter in patients with cerebral vasospasm after subarachnoid hemorrhage. Br J Neurosurg 2012;26:517-24.

22. Weant KA, Ramsey $\mathrm{CN} 3^{\text {rd }}$, Cook AM. Role of intraarterial therapy for cerebral vasospasm secondary to aneurysmal subarachnoid hemorrhage. Pharmacotherapy 2010;30:405-17.

23. Wolf S, Martin H, Landscheidt JF, Rodiek SO, Schurer L, Lumenta CB. Continuous selective intraarterial infusion of nimodipine for therapy of refractory cerebral vasospasm. Neurocrit Care 2010;12:346-51.

24. Firat MM, Gelebek V, Orer HS, Belen D, Firat AK, Balkanci F. Selective intraarterial nimodipine treatment in an experimental subarachnoid hemorrhage model. AJNR Am J Neuroradiol 2005;26:1357-62.

25. Yokota H, Nakabayashi M, Fuse A, Mashiko K, Yamamoto Y, Henmi $\mathrm{H}$, et al. Continuous intracarotid infusion of mannitol in severe head injury. No Shinkei Geka 1993;21:205-11.

26. Domanskaia IA, Kukushkin AA, Mazurok, II, Il'in KL. The regional use of antibiotics in treating craniocerebral trauma and suppurative complications. Vestn Khir Im I I Grek 1993;150:53-6.

27. Kudriavtsev AE, Shikov VG. Intracarotid infusion of drugs in the treatment of purulent meningitis. Sov Med 1976:55-7.

28. Wada J. A new method for the determination of the side of cerebral dominance. A preliminary report of intracarotid injection of sodium amytal in man. Igaku to Seibutsugaki 1949;14:221-2.

29. Wada J, Rassmussen T. Intracarotid injection of sodium amytal for the lateralization of cerebral speech dominance. 1960. J Neurosurg 2007;106:1117-33.

30. Wagner K, Hader C, Metternich B, Buschmann F, Schwarzwald R, Schulze-Bonhage A. Who needs a Wada test? Present clinical indications for amobarbital procedures. J Neurol Neurosurg Psychiatry 2012;83:503-9.

31. Shah AK, Atkinson MD, Gupta P, Zak I, Watson CE, Rothermel R, et al. Transient shivering during Wada test provides insight into human thermoregulation. Epilepsia 2010;51:745-51.

32. Takayama M, Miyamoto S, Ikeda A, Mikuni N, Takahashi JB, Usui K, et al. Intracarotid propofol test for speech and memory dominance in man. Neurology 2004;63:510-5.

33. Castillo M, Mukherji SK, McCartney WH. Cerebral amobarbital sodium distribution during Wada testing: Utility of digital subtraction angiography and single-photon emission tomography. Neuroradiology 2000;42:814-7.

34. Joshi S, Meyers PM, Ornstein E. Intracarotid delivery of drugs: The potential and the pitfalls. Anesthesiology 2008;109:543-64.

35. Bourassa MG. The history of cardiac catheterization. Can J Cardiol 2005;21:1011-4.

36. French JD, West PM, Von Amerongen FK, Magoun HW. Effects of intracarotid administration of nitrogen mustard on normal brain and brain tumors. J Neurosurg 1952;9:378-89.

37. Klopp CT, Alford TC, Bateman J, Berry GN, Winship T. Fractionated intra-arterial cancer; chemotherapy with methyl 
bis amine hydrochloride; a preliminary report. Trans Meet Am Surg Assoc Am Surg Assoc 1950;68:490-511.

38. Wilson CB. Chemotherapy of brain tumors by continuous arterial infusion. Surgery 1964;55:640-53.

39. Wilson CB. Chemotherapy of brain tumors. Adv Neurol 1976;15:361-7.

40. Wilson CB, Gutin P, Boldrey EB, Drafts D, Levin VA, Enot KJ. Single-agent chemotherapy of brain tumors. A five-year review. Arch Neurol 1976;33:739-44.

41. Rapoport SI, Hori M, Klatzo I. Reversible osmotic opening of the blood-brain barrier. Science 1971;173:1026-8.

42. Oldfield EH, Dedrick RL, Chatterji DC, Yeager RL, Girton ME, Kornblith PL, et al. Arterial drug infusion with extracorporeal removal. II. Internal carotid carmustine in the rhesus monkey. Cancer Treat Rep 1985;69:293-303.

43. Oldfield EH, Clark WC, Dedrick RL, Egorin MJ, Austin HA, DeVroom HD, et al. Reduced systemic drug exposure by combining intraarterial cis-diamminedichloroplatinum (II) with hemodialysis of regional venous drainage. Cancer Res 1987;47:1962-7.

44. Oldfield EH, Dedrick RL, Yeager RL, Clark WC, DeVroom HL, Chatterji DC, etal. Reduced systemicdrug exposure by combining intra-arterial chemotherapy with hemoperfusion of regional venous drainage. J Neurosurg 1985;63:726-32.

45. Dedrick RL, Oldfield EH, Collins JM. Arterial drug infusion with extracorporeal removal. I. Theoretic basis with particular reference to the brain. Cancer Treat Rep 1984;68:373-80.

46. Pickrell L, Purvin V. Ischemic optic neuropathy secondary to intracarotid infusion of BCNU. J Clin Neuroophthalmol 1987;7:87-92.

47. Di Chiro G, Oldfield E, Wright DC, De Michele D, Katz DA, Patronas NJ, et al. Cerebral necrosis after radiotherapy and/or intraarterial chemotherapy for brain tumors: PET and neuropathologic studies. AJR Am J Roentgenol 1988;150:189-97.

48. Tonn JC, Roosen K, Schachenmayr W. Brain necroses after intraarterial chemotherapy and irradiation of malignant gliomas: A complication of both ACNU and BCNU? J Neurooncol 1991;11:241-2.

49. Basso U, Lonardi S, Brandes AA. Is intra-arterial chemotherapy useful in high-grade gliomas? Expert Rev Anticancer Ther 2002;2:507-19.

50. Suda K, Nakasu S, Saito A. Ocular complication of combined intracarotid chemotherapy and osmotic blood-brain barrier disruption. Nihon Geka Hokan 1985;54:359-63.

51. Gobin YP, Cloughesy TF, Chow KL, Duckwiler GR, Sayre JW, Milanese K, et al. Intraarterial chemotherapy for brain tumors by using a spatial dose fractionation algorithm and pulsatile delivery. Radiology 2001;218:724-32.

52. Neuwelt E, Abbott NJ, Abrey L, Banks WA, Blakley B, Davis T, et al. Strategies to advance translational research into brain barriers. Lancet Neurol 2008;7:84-96.

53. Hilal SK, Sane P, Mawad ME, Michelsen WJ. Therapeutic interventional radiological procedures in neuroradiology. In: Abrams H, editor. Angiography. $3^{\text {rd }}$ ed. Boston: Little, Brown; 1983. p. 2223-55.

54. Pile-Spellman J. Endovascular therapeutic neuroradiology. Ch. 18. In: Taveras JM, editor. Neuroradiology. $3^{\text {rd }}$ ed. Baltimore: Williams and Wilkins; 1996. p. 1045-179.

55. Dedrick RL. Arterial drug infusion: Pharmacokinetic problems and pitfalls. J Natl Cancer Inst 1988;80:84-9.

56. Lutz RJ, Dedrick RL, Boretos JW, Oldfield EH, Blacklock JB, Doppman JL. Mixing studies during intracarotid artery infusions in an in vitro model. J Neurosurg 1986;64:277-83.

57. Saris SC, Blasberg RG, Carson RE, deVroom HL, Lutz R, Dedrick RL, et al. Intravascular streaming during carotid artery infusions. Demonstration in humans and reduction using diastole-phased pulsatile administration. J Neurosurg 1991;74:763-72.

58. Saris SC, Shook DR, Blasberg RG, Dedrick RL, Doppman JL, Bankiewicz KS, et al. Carotid artery mixing with diastole-phased pulsed drug infusion. J Neurosurg 1987;67:721-5.

59. Saris SC, Wright DC, Oldfield EH, Blasberg RG. Intravascular streaming and variable delivery to brain following carotid artery infusions in the Sprague-Dawley rat. J Cereb Blood Flow Metab 1988;8:116-20.

60. Dedrick RL. Interspecies scaling of regional drug delivery. J Pharm Sci 1986;75:1047-52.

61. Yamane T, Kaneko A, Mohri M. The technique of ophthalmic arterial infusion therapy for patients with intraocular retinoblastoma. Int J Clin Oncol 2004;9:69-73.

62. Pile-Spellman J, Young WL, Joshi S, Duong DH, Vang MC, Hartmann A, et al. Adenosine-induced cardiac pause for endovascular embolization of cerebral arteriovenous malformations: Technical case report. Neurosurgery 1999;44:881-6.

63. HashimotoT,YoungWL,DavisCC,JoshiS,OstapkovichND.Cardiac pause for deliberate systemic hypotension: Dose-response characteristics of adenosine (abstract). Anesthesiology 1999;91:A191.

64. Hashimoto T, Young WL, Aagaard BD, Joshi S, Ostapkovich ND, Pile-SpellmanJ.Adenosine-inducedventricular asystole to induce transient profound systemic hypotension in patients undergoing endovascular therapy: Dose-response characteristics. Anesthesiology 2000;93:998-1001.

65. Joshi S, Wang M, Etu JJ, Pile-Spellman J. Bolus configuration affects dose requirements of intracarotid propofol for electroencephalographic silence. Anesth Analg 2006; 102:1816-22.

66. Wang M, Joshi S. Electrocerebral silence after intracarotid propofol injection is a function of transit time. Anesth Analg 2007;104:1498-503.

67. Joshi S, S MR, Wang M, Chaudhuri D, Straubinger $N$, Straubinger R, et al. The Effectiveness of transient cerebral hypoperfusion assisted intra-arterial delivery of cationic liposomes. J Neurosurg Anesthesiol 2013;25:488-9.

68. Kemeny M. Hepatic artery infusion of chemotherapy as a treatment for hepatic metastases from colorectal cancer. Cancer J 2002;8:S82-8.

69. Stratmann SL. Hepatic artery chemotherapy in the management of colorectal metastases. Proc (Bayl Univ Med Cent) 2002;15:376-9.

70. Sigurdson ER, Ridge JA, Daly JM. Fluorodeoxyuridine uptake by human colorectal hepatic metastases after hepatic artery infusion. Surgery 1986;100:285-91.

71. Zhao M, Chang J, Fu X, Liang C, Liang S, Yan R, et al. Nano-sized cationic polymeric magnetic liposomes significantly improves drug delivery to the brain in rats. J Drug Target 2012;20:416-21.

72. Joshi S, Straubinger R, Singh-Moon R, Wang M, Rai R, Bigio I. Surface charge manipulation of liposomes to enhance intraarterial delivery. J Neurosurg Anesthesiol 2012;24:492-3.

73. Pardridge WM. Lipid mediated transport and carrier-mediated transport. Ch 3. In: Pardridge WM, editor. Brain drug targeting, the future of drug development. Cambridge, UK: Cambridge University Press; 2010. p. 36- 81.

74. Greig NH, Daly EM, Sweeney DJ, Rapoport SI. Pharmacokinetics of chlorambucil-tertiary butyl ester, a lipophilic chlorambucil derivative that achieves and maintains high concentrations in brain. Cancer Chemother Pharmacol 1990;25:320-5.

75. Pardridge WM. Blood-brain barrier transport mechanisms. In: Welch KM, Capalan LR, Reis DJ, Siejo BJ, Weir B, editors Primer on Cerebrovascular Diseases. 1997. p. 21-5.

76. Pardridge WM, Buciak JL, Friden PM. Selective transport of 
an anti-transferrin receptor antibody through the blood-brain barrier in vivo. J Pharmacol Exp Ther 1991;259:66-70.

77. Shi N, Pardridge WM. Noninvasive gene targeting to the brain. Proc Natl Acad Sci U S A 2000;97:7567-72.

78. Friden PM, Olson TS, Obar R, Walus LR, Putney SD. Characterization, receptor mapping and blood-brain barrier transcytosis of antibodies to the human transferrin receptor. J Pharmacol Exp Ther 1996;278:1491-8.

79. Prior R, Reifenberger G, Wechsler W. Transferrin receptor expression in tumours of the human nervous system: Relation to tumour type, grading and tumour growth fraction. Virchows Arch A Pathol Anat Histopathol 1990;416:491-6.

80. Hardebo JE, Kahrstrom J. Endothelial negative surface charge areas and blood-brain barrier function. Acta Physiol Scand 1985;125:495-9.

81. Westergren I, Johansson BB. Altering the blood-brain barrier in the rat by intracarotid infusion of polycations: A comparison between protamine, poly-L-lysine and poly-L-arginine. Acta Physiol Scand 1993;149:99-104.

82. Pardridge WM, Triguero D, BuciakJ. Transport of histone through the blood-brain barrier. J Pharmacol Exp Ther 1989;251:821-6.

83. Strausbaugh LJ, Brinker GS. Effect of osmotic blood-brain barrier disruption on gentamicin penetration into the cerebrospinal fluid and brains of normal rabbits. Antimicrob Agents Chemother 1983;24:147-50.

84. Xia H, Gao X, Gu G, Liu Z, Zeng N, Hu Q, et al. Low molecular weight protamine-functionalized nanoparticles for drug delivery to the brain after intranasal administration. Biomaterials 2011;32:9888-98.

85. Xu F, Lu W, Wu H, Fan L, Gao X, Jiang X. Brain delivery and systemic effect of cationic albumin conjugated PLGA nanoparticles. J Drug Target 2009;17:423-34.

86. Lu W. Adsorptive-mediated brain delivery systems. Curr Pharm Biotechnol 2012;13:2340-8.

87. Lu W, Sun Q, Wan J, She Z, Jiang XG. Cationic albumin-conjugated pegylated nanoparticles allow gene delivery into brain tumors via intravenous administration. Cancer Res 2006;66:11878-87.

88. Lu W, Wan J, She Z, Jiang X. Brain delivery property and accelerated blood clearance of cationic albumin conjugated pegylated nanoparticle. J Control Release 2007;118:38-53.

89. Lu W, Zhang Y, Tan YZ, Hu KL, Jiang XG, Fu SK. Cationic albumin-conjugated pegylated nanoparticles as novel drug carrier for brain delivery. J Control Release 2005;107:428-48.

90. Sharma G, Modgil A, Zhong T, Sun C, Singh J. Influence of short-chain cell-penetrating peptides on transport of doxorubicin encapsulating receptor-targeted liposomes across brain endothelial barrier. Pharm Res 2013.

91. Qin Y, Chen H, Zhang Q, Wang X, Yuan W, Kuai R, et al. Liposome formulated with TAT-modified cholesterol for improving brain delivery and therapeutic efficacy on brain glioma in animals. Int J Pharm 2011;420:304-12.

92. Qin Y, Zhang Q, Chen H, Yuan W, Kuai R, Xie F, et al. Comparison of four different peptides to enhance accumulation of liposomes into the brain. J Drug Target 2012;20:235-45.

93. Gupta B, Levchenko TS, Torchilin VP. TAT peptide-modified liposomes provide enhanced gene delivery to intracranial human brain tumor xenografts in nude mice. Oncol Res 2007;16:351-9.

94. Joshi WM, Singh-Moon R. Feasibility of intra-arterial drug delivery to brain tissue using cell penetrating peptides. J Neurosurg Anesthesiol 2013;25:465.

95. Joshi S, Aagaard B, Pile-Spellman J, Libow A, Popilskis SJ. In Non-human primates intracarotid adenosine-not nitroprusside-profoundly increases cerebral blood flow. Anesthesiol 2000;93:362.

96. Mourant JR, Johnson TM, Los G, Bigio IJ. Non-invasive measurement of chemotherapy drug concentrations in tissue: Preliminary demonstrations of in vivo measurements. Phys Med Biol 1999;44:1397-417.

97. Bigio IJ, Mourant JR, Los G. Noninvasive, in-situ measurement of drug concentrations in tissue using optical spectroscopy. J Gravit Physiol 1999;6:P173-5.

98. Bigio IJ, Bown SG. Spectroscopic sensing of cancer and cancer therapy: Current status of translational research. Cancer Biol Ther 2004;3:259-67.

99. Reif R, Wang M, Joshi S, A'Amar O, Bigio IJ. Optical method for real-time monitoring of drug concentrations facilitates the development of novel methods for drug delivery to brain tissue. J Biomed Opt 2007;12:034036.

100. Weber JR, Cuccia DJ, Johnson WR, Bearman GH, Durkin AJ, Hsu $\mathrm{M}$, et al. Multispectral imaging of tissue absorption and scattering using spatial frequency domain imaging and a computed-tomography imaging spectrometer. J Biomed Opt 2011;16:011015.

101. Cuccia DJ, Bevilacqua F, Durkin AJ, Ayers FR, Tromberg BJ. Quantitation and mapping of tissue optical properties using modulated imaging. J Biomed Opt 2009;14:024012.

102. Cuccia DJ, Bevilacqua F, Durkin AJ, Tromberg BJ. Modulated imaging: Quantitative analysis and tomography of turbid media in the spatial-frequency domain. Opt Lett 2005;30:1354-6.

103. Ergin A, Wang M, Zhang J, Bigio I, Joshi S. Noninvasive in vivo optical assessment of blood brain barrier permeability and brain tissue drug deposition in rabbits. J Biomed Opt 2012;17:057008.

104. Singh-Moon RW, Chaudhuri D, Straubinger N, Straubinger R, Bigio IJ, Joshi S. Optical pharmacokinetic tomography: Linear, planar, and spatial mapping of tracer tagged intra-arterial nanoparticle delivery. J Neurosurg Anesthesiol 2013;25:465-6.

105. Pardridge WM. Brain drug targeting, the future of drug development. Cambridge, UK: Cambridge University Press; 2010.

106. Joshi S, Young WL, Pile-Spellman J, Duong DH, Vang MC, Hacein-Bey L, et al. The feasibility of intracarotid adenosine for the manipulation of human cerebrovascular resistance. Anesth Analg 1998;87:1291-8.

107. Joshi S, Agarwal S. The proposed role of optical sensing in translational stroke research. Ann N Y Acad Sci 1199:149-57.

How to cite this article: Joshi S, Ellis JA, Emala CW. Revisiting intra-arterial drug delivery for treating brain diseases or is it "déjàvu, all over again"?. J Neuroanaesthesiol Crit Care 2014;1:108-15.

Source of Support: NIH R01s CA127500, CA138643, Conflict of Interest: None declared. 